\title{
Information Acquisition Decisions and the Choice of Financial Year-Ends
}

\author{
by
}

Dov Fried* and Nishi Sinha**

Tisch Hall, Suite 300,

Stern School of Business,

New York University,

40 West 4th Street,

New York, NY 10012.

October 1998

We thank Jeff Callen, Jack Hughes, Suresh Radhakrishnan, and Shyam Sunder and for valuable comments. This paper also benefited from the comments of participants of the 1998 AAA meetings where it was presented.

**Corresponding Author: $\quad$ *email: hfried@stern.nyu.edu

Nishi Sinha

(212) 998-0026

email: nsinha@stern.nyu.edu 


\title{
Information Acquisition Decisions and the Choice of Financial Year-Ends
}

\begin{abstract}
In some industries the financial-year-ends of member firms are clustered together whereas in others they are more widely dispersed. This study attempts to provide an explanation for this phenomenon. Recognizing that financial-year-ends are not just the time when firms disclose information but also the time when they acquire information (when books are closed), we frame this study in the larger economic context of determining the optimal timing of information acquisition and release. Prior studies have examined the frequency with which firms acquire costly information. We address a question that follows naturally: given that information is acquired only once every t operating periods, when during the t period should such an exercise take place? We also examine a related question: do competing firms have any incentive to share the information acquisition burden?

The results of our analysis indicate that firms' choice of their financial year-end may partially be driven by the degree of correlation between the firms' cost (and demand) parameters and the incentives to share the information acquisition burden. Duopolists that face random but permanent shocks to their linear cost (or demand) parameter every period, but who can collect information in only some of the periods, will choose identical yearends (that which is dictated by the stochastic environment) unless their costs are very strongly correlated (almost close to 1). Only when their costs are highly correlated do the firms choose staggered year-ends. Whether yearends are clustered or staggered are also shown to be a function of the differences in cost variances for the two firms.
\end{abstract}




\section{Information Acquisition Decisions and the Choice of Financial Year-Ends}

\section{Introduction}

Firms that operate in a changing environment must update their information periodically. Since information collection is costly, such updating may not be feasible in every period or prior to every operating decision. With this in mind, prior studies have examined the frequency with which firms acquire costly information. In this study we examine a question that follows naturally: given that information will be acquired a predetermined number of times (e.g. once) every t operating periods, when during the t periods should such an exercise(s) take place? In addition, if the acquired information is to be publicly disclosed such that it becomes available to competitors, how will competing firms choose the acquisition and disclosure timing?

The answers to these questions are relevant to an understanding of firms' choice of financial year-ends. Typically, a firm's financial year-end (or the end of its quarterly interim period) is the time when it (a) collects and collates information (when accounting books are closed) and (b) publicly releases its financial report. The timing choice examined here, wherein the timing of information acquisition and release are coincident, is consistent with the decision faced by firms in choosing their financial year-ends. To date little research exists on this issue. An examination of the financial year-ends for firms included in the 1996 Compustat tapes indicates that although in many industries the year-ends are concentrated at 12/31, the degree of concentration varies widely between industries. ${ }^{1}$ One possible reason for this dispersion or uniformity in timing could well be a consideration by firms of the competitive impact of the timing of their reports. ${ }^{2}$

\footnotetext{
${ }^{1}$ For example, in industries such as computer communications equipment, semiconductors, software, computer integrated systems (SIC codes 3571, 3674, 7372, and 7373, respectively) only about half the firms choose 12/31 as their year-end, the rest are distributed over other months. In industries such as petroleum refining and oil and gas extraction and in regulated industries such as insurance, banks (SIC codes 2911, 1311, 6311, 6021) there appears to be far more uniformity.

2 The choice of financial year-ends is governed by factors other than competitive concerns as well. The seasonality in some businesses may determine this choice. For instance, in the retail industry most financial year-
} 
This paper investigates the impact of both stochastic and competitive environments on firms' information acquisition and disclosure decisions. To isolate the impact of the stochastic environment, we first examine a monopolist's optimal timing when his linear cost (or demand) parameter is subject to random but permanent shocks in each of $\mathrm{t}$ operating periods. The monopolist can acquire information only a few times $(<\mathrm{t})$ during the $\mathrm{t}$ periods. The results from this analysis serve as a setting for our next scenario where we introduce a competitor with correlated costs. Since both firms operate in the same stochastic environment, in the absence of competitive concerns both firms will acquire information at the same exact time, this timing being identical to the one chosen by the monopolist in the preceding analysis. However, the presence of a competitor (who gets to observe their disclosed report) may cause the firms to deviate from this "stochastically-optimum" timing and alter their information acquisition and disclosure patterns.

If publicly release financial reports of competitors are informative to other firms, these reports can serve as an alternate means of information acquisition and may offer the nondisclosing firms additional opportunities to update their information. If firms stagger the release date of their reports, they can update their information (based on the other firm's report) part-way through their own financial year. Thus, in an duopoly each firm can update its information twice during the year. On the other hand, if they release their reports simultaneously, each firm updates its information only once.

Our results indicate that, given the stochastic environment described here, the monopolist spreads his information acquisition activities evenly over time. More interestingly, we find that the first information gathering exercise takes place not at the beginning of the first operating period, but only after initially going a number of periods without any new information. The intuition for this result is as follows. If the monopolist investigates costs early, as time passes this early-acquired data becomes less and less informative about later periods. On the other hand, by delaying the investigation the value of the information eventually gathered may be greater, but that superior information can only be exploited for the few remaining periods. As a result of these

ends are in January or February, when inventory levels are at post-Christmas lows. As another example, firms in most regulated industries do not have discretion in choosing their financial year-ends. 
tradeoffs between early versus late gathering of information, the monopolist acquires information only after a few initial periods but before the final period.

For the duopolists, we find that unless the costs of the two firms are very strongly correlated (almost close to 1), firms will choose to acquire and disclose at the same time. Only when the costs are almost perfectly correlated do the firms choose staggered acquisition and disclosure. This suggests that we are more likely to see staggered financial year-ends in industries with very similar firms, i.e., similar with respect to technology and cost structures. The results also suggest that competitive concerns, whether in terms of learning from rivals' reports or preventing rivals from learning from one's own report, play a role secondary to that of the stochastic environment in determining the choice of financial year-ends. ${ }^{3}$

Our results may also be relevant to empirical research that uses financial year-ends as a sample selection criteria. Using such criteria introduces a selection bias the nature of which this study attempts to explain. For instance, studies on intraindustry information transfers (e.g., Foster (1981) and Frost (1995)) hypothesize that the strength of such transfers is positively correlated with within-industry homogeneity. Our results suggest that the greater the within-industry homogeneity, more likely it is for firms to choose dispersed financial year-ends. Therefore, by restricting attention to firms that have the same financial year-end (December 31) these studies may be including relatively dissimilar firms, thereby downward biasing their results.

Finally, numerous prior studies have looked at trade associations as a mechanism for firms to share information with their industry comembers. Similar to the present study, these information sharing studies are also about simultaneous acquisition and release of information firms acquire more precise information in return for revealing their private signals to the trade association. However, trade associations, by law, are required to release only aggregated (and

\footnotetext{
3 The stochastic environment in our model is such that firms face a random but permanent shock to their costs every period. To make the stochastic environment "less severe", an alternative approach would be to allow that the shocks are only semi-permanent (i.e., allow a Markovian rather than a strictly random walk structure on costs). However, this modification makes the model exceedingly complicated and does not allow for closed-form analytical solutions.
} 
not firm-specific) data to the members. Therefore, timing issues of the kind examined here, where each firm has the option of revealing separately, cannot be examined in the trade association setting. In this study we examine (what amounts to) a novel mechanism for competing firms to collaborate in sharing information; firms "share" information by agreeing to release their reports at different times. Despite the apparent similarities in the two settings, however, we find that the degree of collaboration typically found in information sharing studies does not carry over (but rather is inversely related) to information acquisition decisions of the kind examined here. The intuition for this divergence in results is explained later.

The remainder of the paper proceeds as follows. The next section provides a brief review of the literature on information acquisition in general and information sharing in competitive environments. Section 3 describes the model. Section 4 analyzes the timing decision of the monopolist whereas Section 5 is devoted to the duopolists' acquisition and disclosure decisions. Section 6 provides a summary and conclusions.

\section{Background Literature}

\subsection{Information Acquisition}

Few studies have analyzed the information acquisition choices of firms. In an infinite horizon model, Hughes $[1975,1977]$ investigates the optimal timing for obtaining (costly) reports about an underlying Markovian process. The firm weighs the costs of not investigating a potentially out of control process which leads to higher operating costs, against the costs of investigating the process and rectifying it if it is found to be out of control. Similar to our study, when reports yield perfect information, Hughes [1975] shows that the optimal policy calls for equally-spaced investigative reports. When reports are imperfectly informative, Hughes [1977] shows that there are benefits to acquiring cost information from other than the most recent period. In contrast to our study, though, he does not investigate the impact of competition in such choices, and his modeling of the stochastic environment (a stationary state Markovian process) is different from ours. 
Hansen and Sankar [1998] look for the length of the data acquisition cycle in industries where costs follow a first order autoregressive process. Our focus, in contrast, is on the timing within a particular data acquisition cycle. Li, McKelvy, and Page [1986] examine optimal research by oligopolists in a one-period two-stage game in which each firm first invests in costly research, and then with the information so gathered, competes in the product market. The focus is on the optimal amount of research that the oligopolists individually undertake, where the greater the research, the higher the precision of the signal concerning the uncertain parameter. Similarly, in the context of a stochastic Cournot oligopoly with convex costs, Kirby [1993] also investigates the optimal amount of information to acquire, where the choice is in terms of the number of noisy (and costly) signals to acquire. In contrast, we look for the best timing for research in a multi-period setting in which we assume that research yields perfect information for the investigating firms.

\subsection{Information Sharing by Duopolists}

Numerous prior studies have documented the incentives of firms to precommit to mutual sharing of information with their industry comembers through mechanisms such as trade associations. ${ }^{4}$ In this study we examine what amounts to an alternative mechanism for sharing information; in our setup firms share information by releasing their financial reports at different times. As such, it is instructive to review the relevant literature on information sharing in oligopolies. Prior research has established that in a homogenous good Cournot oligopoly with linear demand and constant unit costs, and with truthful information sharing, the degree of information sharing through mechanisms such as trade associations is dependent on

- the precision of the signals received and

- the correlation between the firms' stochastic parameters. The greater the correlation the less incentive there is for firms to share information. 5

4 See, for instance, Novshek and Sonnenschein [1982], Fried [1984], Vives [1986], Jin [1992], Raith [1993].

5 Besides the degree of correlation between the firms' stochastic parameters, other factors that affect the information sharing incentives are: degree of product differentiation, substitutes versus complements, Cournot 
When each firm receives perfect signals on its own costs, sharing information with a rival does not improve the firm's information about its own costs, but leads only to improved information regarding the rivals' reactions. Fried [1984], Sakai [1986] and Shapiro [1986] examined such a setting when the uncertain parameters were imperfectly correlated across firms $(0<\mathrm{r}<1)$, and found that sharing of such information is mutually beneficial. Fried [1984] also found that when only one duopolist gathers information, it still might be beneficial for that duopolist to (unilaterally) disclose the information to his rival. Those benefits, however, are dependent on $\mathrm{r}$. As $\mathrm{r}$ approaches 1, it may be harmful to disclose unilaterally.

The model we examine is a multiperiod extension of models similar to Fried [1984], Sakai [1986] and Shapiro [1986] in that firms receive perfect signals on their costs. Whereas in the information sharing literature a firm may choose not to share information to minimize competitive costs, in our setting nondisclosure is not an option. Firms must reveal their information, their only choice is about the timing.

\section{The Model}

Consider a product market with a linear demand curve and constant marginal costs, such that the inverse demand curve in period $t$ is given by:

$$
\operatorname{Price}(t)=A-d Q(t)
$$

where $Q$ is the aggregate output of all firms, and $\mathrm{d}$ is a known constant (set equal to 1 without loss of generality).

Let $C_{i}(t)=c+w_{i}(t)$ be the unit marginal cost of firm $\mathrm{i}$ for period $\mathrm{t}$, where $\mathrm{c}$ is the deterministic component (set equal to 0 without loss of generality) and $\mathrm{w}_{\mathrm{i}}(\mathrm{t})$ is the stochastic component. In each period $\mathrm{k}$, firm i's costs receive a random but permanent shock $u_{i}(k)$, such that costs in period $t$ are a sum of all random shocks received in prior periods. Therefore,

versus Bertrand competition, convexity of costs, the precision and correlation of the signals etc. Raith [1993] provides a good summary of the relevant literature. 


$$
w_{i}(t) \equiv \sum_{k=1}^{t} u_{i}(k)
$$

Alternatively stated, we assume that unit costs follow a random walk process. This formulation has the realistic property that as time passes, older information becomes less informative regarding future cost conditions. $u_{i}(k)$ is i.i.d. Normal, with mean 0 and variance $v_{i}^{2}$ for all $\mathrm{k}$. Thus, Variance $\left(\mathrm{w}_{\mathrm{i}}(\mathrm{k})\right)=\mathrm{kv}_{\mathrm{i}}^{2}$.

In periods prior to the first information collection exercise, the expected unit costs $E(w(t))$ are equal to 0 , the prior mean. It is assumed that information collection by firm $\mathrm{i}$ at the beginning of period $\mathrm{j}$ (prior to making its production choice in that period) yields perfect knowledge of $\mathrm{w}_{\mathrm{i}}(\mathrm{j}) .^{6} \quad$ From period $\mathrm{j}$ onwards $E(w(t))=w(j)$, till information is updated again. Given the information available at the beginning of any period, each firm maximizes expected profits. Profits for firm i in period $t$ are given by:

$$
P_{i}(t)=\left(A-C_{i}(t)-Q(t)\right) q_{i}(t)=\left(A-w_{i}(t)-Q(t)\right) q_{i}(t)
$$

The time horizon is made up of $\mathrm{T}$ operating periods, where production decisions are made at the beginning of each period t, but information is gathered and released in only some of the periods. The decision regarding when to collect information (that is, at the beginning of which period(s)) is made before the start of the first period, at time $t_{0}$. The sequence of events is as follows:

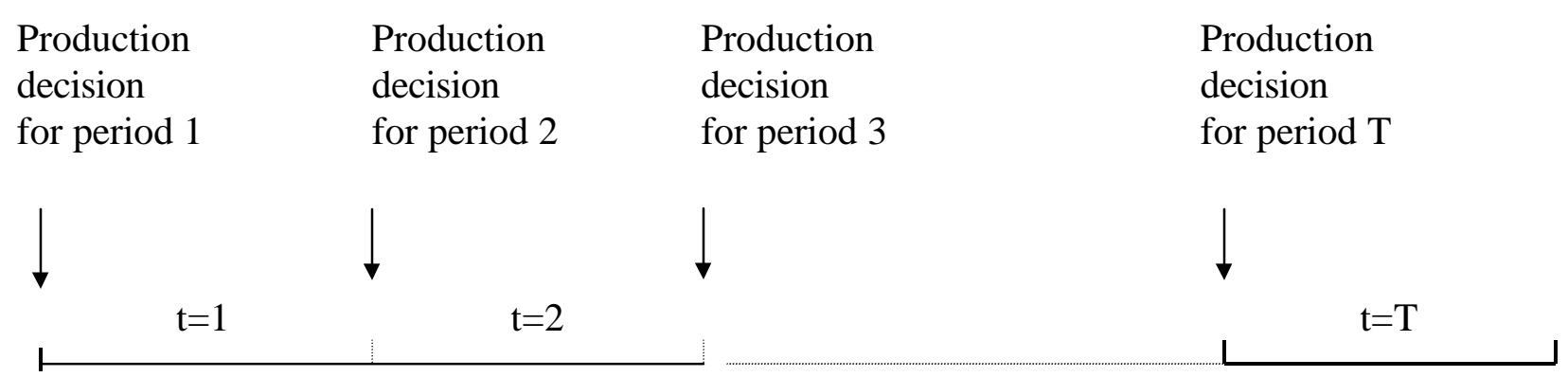

\footnotetext{
6 Note that we do not include in this model a cost for acquiring information. This cost will be of importance in determining how often to collect information, but once this frequency is determined, such costs are not likely to influence the timing of information collection.
} 


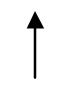

$\mathrm{t}=\mathrm{t}_{0}$

Firms decide

the timing for

collecting/disclosing information

\section{$\uparrow$}

$\mathrm{t}=\mathrm{t}_{1}$

Information

collected/disclosed for

the first time

Figure 1. Time line (with first information collection at beginning of period 3) 
This sequence of events described above is consistent with a setting where a financial year (or quarter) is made up of several operating periods, and in which information is collected once during the financial year (or quarter), and not prior to every operating period.

\subsection{Tradeoffs in the Timing of Information Acquisition}

For problems of this nature, the optimal production decision is of the form

$$
q_{i}^{*}(t)=\frac{A-E\left(w_{i}(t)\right)-\left(Q(t)-q_{i}^{*}(t)\right)}{2}
$$

and expected profits are $\left.\mathrm{E}\left(\mathrm{q}_{\mathrm{i}}{ }^{*} \mathrm{t}\right)\right)^{2}$. Since expected profit is convex in the quantity produced, expected profit will increase as the variability of output increases. If no information is collected, expected $\operatorname{Variance}\left(q_{i}^{*}\right)=0$. If information is collected in period $\mathrm{t}$, expected $\operatorname{Variance}\left(q_{i}^{*}\right)$ is an increasing function of Variance $\left(E\left(w_{i}(t)\right)\right.$, which, in turn, is an increasing function of $t$. This is the source of the tradeoffs in our model. When a firm delays gathering information in any period, profits are "lost" in that period. The tradeoff, however, is that by delaying the acquisition of information, the value of the information eventually gathered is greater as Variance $\left(E\left(w_{i}(t)\right)\right.$ increases as $\mathrm{t}$ increases. However, that superior information can only be exploited for the remaining periods.

\section{Information Acquisition by a Monopolist}

Consider the case of a monopolist facing random but permanent shocks to his $\operatorname{costs}^{7}$ in every one of $\mathrm{T}$ periods. He makes production decisions in each of these periods, but can acquire information only $n$ times over the T periods $(n \leq T)$. His profits in any period $t$ are given by $P(t)=(A-w(t)-q(t)) q(t)$. From (3), his production decision will be

\footnotetext{
7 In keeping with the framework until now, our discussion will be in terms of the monopolist's cost parameter. However, given that costs as well as demand are linear, the results would be identical if we assumed that the demand intercept A faced random shocks.
} 


$$
q^{*}(t)=\frac{A-E(w(t))}{2}
$$

Prior to collecting information, $E(w(t))=0$, the prior mean. Let $\mathrm{t}_{\mathrm{i}}$ represent the period in which the monopolist gathers information for the ith time. Information acquisition at the beginning of period $\mathrm{t}_{\mathrm{i}}$ reveals $\mathrm{w}\left(\mathrm{t}_{\mathrm{i}}\right)$ perfectly and $E\left(w\left(t_{i}\right)\right)=w\left(t_{i}\right)$. Also, from period $\mathrm{t}_{\mathrm{i}}$ onwards $E(w(t))=w\left(t_{i}\right)$, till information is updated again in period $\mathrm{t}_{\mathrm{i}+1}$.

It is straightforward to show that his expected profits for any given period $t$ are equal to

$$
\begin{array}{cc}
\mathrm{P}^{*}(\mathrm{t})=E\left[q^{*}(t)\right]^{2}=E\left[\frac{A-E\left(w\left(t_{i}\right)\right)}{2}\right]^{2}=\left[\frac{A^{2}+\operatorname{Variance}(\mathrm{E}(w(t)))}{4}\right] & \text { where } \\
\operatorname{Variance}(\mathrm{E}(w(t)))=0 & \text { for } \mathrm{t}<\mathrm{t}_{1} \text { and } \\
=\mathrm{t}_{\mathrm{i}} \mathrm{V}^{2} & \text { for } \mathrm{t}_{\mathrm{i}} \leq \mathrm{t}<\mathrm{t}_{\mathrm{i}+1}
\end{array}
$$

with the inner expectations in (4) taken at the beginning of period $t$, and the outer ones at time $t_{0}$.. Equalities (5.1) and (5.2) follow from the fact that $\mathrm{w}(\mathrm{t}) \equiv \sum_{k=1}^{t} u(k), \mathrm{E}(\mathrm{u}(\mathrm{t}))=0$, and that $\mathrm{u}(\mathrm{k})$ are serially uncorrelated. Total expected profit over all the $\mathrm{T}$ periods (where the expectation is taken at the beginning of period 1 at time $t_{0}$ ) is given by :

$$
P^{*}=\frac{T A^{2}}{4}+\sum_{i=1}^{n}\left(t_{i}-t_{i-1}\right) \frac{t_{i-1} v^{2}}{4}+\left(T+1-t_{n}\right) \frac{t_{n} v^{2}}{4}
$$

The monopolist will maximize expected profit by acquiring information as per the following proposition.

Proposition 1: For a monopolist gathering cost or demand information $n$ times in $T$ subperiods $(n \leq T)$, new information will be gathered at the beginning of every $(T+1) /(n+1)$ th period.

Proof: See Appendix A1. 
According to the Proposition, the monopolist will gather information evenly over time, at equally spaced intervals. ${ }^{8}$ The results also show that $(T+1) /(n+1)$ periods will pass before the first information gathering exercise. For instance,

- if $\mathrm{n}=1$ (information is acquired only once over the $\mathrm{T}$ periods), information will be gathered at the half way point; i.e.,

$$
\mathrm{t}_{1}=\frac{(T+1)}{2}
$$

- if $\mathrm{n}=2$ (information is collected twice), then information is gathered at the "one-third" and "two-thirds" points; i.e.,

$$
\mathrm{t}_{1}=\frac{(T+1)}{3} \text { and } \mathrm{t}_{2}=\frac{2(T+1)}{3} .
$$

The firm is therefore willing to remain uninformed for some initial periods in order to get better information later. The intuition for this result follows from our discussion earlier. Delaying information means foregone expected profits; however, the information eventually gathered is worth more. This pattern of evenly-spaced information collection follows directly from the random walk characteristics of costs. ${ }^{9}$ We make use of these results later in our discussion of the duopolists' problem.

\section{Information Acquisition by Duopolists}

To examine the impact of competition on the timing of the information acquisition exercises, we now consider a homogenous good market with two firms whose costs are correlated. Each firm's costs behave as the costs of the monopolist described in section 3, with the additional assumptions as to the cross-sectional correlation:

\footnotetext{
8 Depending on the value of $\mathrm{T}$, the ratio $(\mathrm{T}+1) /(\mathrm{n}+1)$ need not be an integer. In that case the length of time between two adjacent acquisition exercises is identical, except that the interval following the last point of acquisition may be shorter.

${ }^{9}$ Costs that have different autoregressive properties will yield a different time-pattern.
} 
(a). Covariance $\left(u_{i}(k), u_{j}(k)\right)=\operatorname{rv}_{i} v_{j}$ where $r$ is the coefficient of correlation.

and

(b). Covariance $\left(\mathrm{u}_{\mathrm{i}}(\mathrm{k}), \mathrm{u}_{\mathrm{j}}(\mathrm{l})\right)=0$

Assumption (a) means that in any given period $\mathrm{k}$ the shocks to firm i and firm j's costs are correlated, with $r$ as the coefficient of correlation. Assumption (b) states that the random shocks are serially uncorrelated. Since $w_{i}(t) \equiv \sum_{k=1}^{t} u_{i}(k)$, these assumptions together imply that the covariance of the two firms' costs in any period $\mathrm{k}=\operatorname{Covariance}\left(\mathrm{w}_{\mathrm{i}}(\mathrm{k}), \mathrm{w}_{\mathrm{j}}(\mathrm{k})\right)=\mathrm{kr} \mathrm{v}_{\mathrm{i}} \mathrm{v}_{\mathrm{j}}$.

As long as a firm's costs are not revealed to its rival, each firm will collect information exactly as the monopolist in the prior section. However, allowing for the possibility of information revelation to the rival changes the incentives significantly. Since the firms' costs are correlated, knowledge of the rival's costs is informative about one's own costs as well. Thus, instead of each firm individually undertaking the expense of investigating its costs every period, firms may benefit by coordinating their information acquisition/disclosure exercises. For instance, this can be done by staggering their financial year-ends, such that a firm can learn from the publicly disclosed financial reports of other firms, and get an updated signal on its costs before its own year-end when it collects its cost information. The benefits of such an arrangement would be the increased frequency with which firms get information on their cost estimates. Each firm would get two signals (as against only one) about its costs - one a perfect one (from its own investigative activities), the other a noisy one (from the rival's cost information). In such an arrangement we look for the timing of the information gathering exercises that the two firms will commit to ex ante.

We further assume that since investigating costs is an expensive exercise, each duopolist investigates his costs only once every $\mathrm{T}$ periods. Such an investigation yields perfect information regarding the investigating firm's costs in all prior periods as well as the current period. The sequence of events is as follows (see Figure 1 for time line). The duopolists noncooperatively make production choices at the beginning of each of $\mathrm{T}$ periods. In addition, at the start of period 1 the duopolists decide when each duopolist will collect information regarding his costs. This is reflective of the choice of financial year-ends by firms whose financial years are made up of 
several operating cycles. Once chosen, firms are committed to their financial year-ends. This prevents the information sharing arrangement from unraveling ex-post, since financial reports must be released at the chosen financial year-end.

\subsection{Analysis and Results}

We assume that if it is agreed that information is to be collected by the two firms at different points in time, duopolist $\mathrm{f}$ will be the first one to acquire the information and that information will be gathered at time $\mathrm{t}_{1} \cdot{ }^{10}$ The second duopolist, duopolist $\mathrm{s}$, will gather information at $t_{2}\left(\begin{array}{lll}t_{2} & t & 1\end{array}\right)$. Firm $f(s)$ chooses $t_{1}\left(t_{2}\right)$ to maximize the sum of the expected profits from all the $\mathrm{T}$ operating periods. Then expected profits over $\mathrm{T}$ periods (expectation taken at the beginning of period 1 , at time $\mathrm{t}=\mathrm{t}_{0}$ ) are given by (see Appendix $\mathrm{A} 2$ for derivation):

$$
\begin{aligned}
& \mathrm{P}_{\mathrm{f}}^{*}=\mathrm{T}\left(\frac{\mathrm{A}^{2}}{9}\right)+[\mathrm{F} 1]\left(\mathrm{t}_{2}-\mathrm{t}_{1}\right)+[\mathrm{F} 2]\left(\mathrm{T}+1-\mathrm{t}_{2}\right) \\
& \mathrm{P}_{\mathrm{s}}^{*}=\mathrm{T}\left(\frac{\mathrm{A}^{2}}{9}\right)+[\mathrm{S} 1]\left(\mathrm{t}_{2}-\mathrm{t}_{1}\right)+[\mathrm{S} 2]\left(\mathrm{T}+1-\mathrm{t}_{2}\right)
\end{aligned}
$$

where

- $\frac{\mathrm{A}^{2}}{9}$ is the profit that would have accrued in the absence of any information gathering.

- F1 (S1) represents the increase (over $\frac{\mathrm{A}^{2}}{9}$ ) in f's (s's) expected profits resulting from the information acquired in period $t_{1}$ by duopolist $\mathrm{f}$. Since that term is positive for both duopolists both benefit from the information acquisition (and sharing) done by duopolist $\mathrm{f}$. That benefit is fixed until period $t_{2}$.

- F2 (S2) represents the increase (over $\frac{\mathrm{A}^{2}}{9}$ ) in firm f's (s's) expected profits resulting from the information acquired in period $t_{2}$ by duopolist $s$. That term is also positive and the benefit 
from information acquisition and sharing stays at their respective levels for each duopolist for the remaining $\left(T+1-t_{2}\right)$ periods.

- $\mathrm{F} 1=\frac{\left(\mathrm{b}_{\mathrm{f}}-2\right)^{2} \mathrm{t}_{1} \mathrm{v}_{\mathrm{f}}^{2}}{9}$

- $\mathrm{F} 2=\frac{\left(1-2 \mathrm{Hb}_{\mathrm{s}}\right)^{2} \mathrm{t}_{2} \mathrm{v}_{\mathrm{s}}^{2}}{9}+\frac{4 \mathrm{G}^{2} \mathrm{t}_{1} \mathrm{v}_{\mathrm{f}}^{2}}{9}+\frac{4\left(2 \mathrm{Hb}_{\mathrm{s}}-1\right) \mathrm{Gt}_{1} \mathrm{rv}_{\mathrm{f}} \mathrm{v}_{\mathrm{s}}}{9}$

- $\mathrm{S} 1=\frac{\left(1-2 \mathrm{~b}_{\mathrm{f}}\right)^{2} \mathrm{t}_{1} \mathrm{v}_{\mathrm{f}}^{2}}{9}$

- $\mathrm{S} 2=\frac{\left(\mathrm{Hb}_{\mathrm{s}}-2\right)^{2} \mathrm{t}_{2} \mathrm{v}_{\mathrm{s}}^{2}}{9}+\frac{\mathrm{G}^{2} \mathrm{t}_{1} \mathrm{v}_{\mathrm{f}}^{2}}{9}+\frac{2\left(\mathrm{Hb}_{\mathrm{s}}-2\right) \mathrm{Gt}_{1} \mathrm{rv}_{\mathrm{f}} \mathrm{v}_{\mathrm{s}}}{9}$

- $\quad \mathrm{v}_{\mathrm{f}}^{2}$ and $\mathrm{v}_{\mathrm{s}}^{2}$ are the variances of the random shock terms

- $\mathrm{b}_{\mathrm{f}}=\mathrm{rv} \mathrm{v}_{\mathrm{s}} / \mathrm{v}_{\mathrm{f}}$ and $\mathrm{b}_{\mathrm{s}}=\mathrm{rv}_{\mathrm{f}} / \mathrm{v}_{\mathrm{s}}$

- $\mathrm{G}=\left(\frac{\mathrm{t}_{2}\left(1-\mathrm{r}^{2}\right)}{\mathrm{t}_{2}-\mathrm{t}_{1} \mathrm{r}^{2}}\right)$ and $\mathrm{H}=\left(\frac{\mathrm{t}_{2}-\mathrm{t}_{1}}{\mathrm{t}_{2}-\mathrm{t}_{1} \mathrm{r}^{2}}\right)$

Note that even though the acquired information is disclosed to the rival, the net payoff is positive for all values of the parameter for both duopolists; that is, the benefits of improved information outweigh the loss from disclosing this information to the rival. Equations (7.1) and (7.2) do not lend themselves to tractable closed form solutions in all cases. However, results can be found for the two boundary cases $r=0$ and $r=1$. The results of these cases make for interesting comparisons with the information sharing results and the monopoly results of section 4 .

Proposition 2: When $r=0$, both duopolists acquire information at the same time and $t_{1}=t_{2}=$ $\frac{(\mathrm{T}+1)}{2}$.

Proof: See Appendix A3.

10 This is not an innocuous assumption, since there may be (as we shall see) benefits to being the first or second acquirer. However, we can motivate this by thinking of $\mathrm{f}$ as an existing firm which has already chosen its financial year-end, and s as a later entrant in the industry. 
Proposition 3: When $r=1$, information acquisition is spread evenly over the $T$ periods and $t_{1}=$ $\frac{(\mathrm{T}+1)}{3}$ and $t_{2}=\frac{2(\mathrm{~T}+1)}{3}$.

Proof: : See Appendix A3.

Proposition 2 shows that when the duopolists' costs are completely independent, there is no incentive for collaborating on the timing of research. Each firm collects information as the monopolist in the previous section, at the half-way point. At the other extreme, Proposition 3 shows that when the duopolists costs are perfectly correlated, the two firms take turns in acquiring information and spread out their information gathering exercises at equally-spaced intervals.

\subsection{Numerical Analysis}

Before proceeding to a discussion of the results, we need to address what happens between the extreme cases of $r=0$ and $r=1$. Since we could not get a closed form solution which maximizes equations (7.1) and (7.2), we used numerical analysis varying $r$ between 0 and 1 by 0.1 and varying the relative proportion of $\mathrm{v}_{1}$ to $\mathrm{v}_{2}$ from 1:1 to 1:25.

When the variances were equal $\left(\mathrm{v}_{1} / \mathrm{v}_{2}=1\right)$, the duopolists staggered their information acquisition only when $r$ reached 0.995 . For values of $r$ lower than 0.995 simultaneous acquisition at $\frac{(\mathrm{T}+1)}{2}$ was always a solution, and for relatively higher values of $\mathrm{r}$ in this range multiple equilibria were possible. When there was more than one equilibrium, the highest payoff for both players occurred at the equilibrium $\mathrm{t}_{1}=\mathrm{t}_{2}=\frac{(\mathrm{T}+1)}{2}$.

Table 1 illustrates these results for $\mathrm{T}=11, \mathrm{r}=0.3$ and $\mathrm{r}=0.9$ when the variances are equal. The rows (columns) indicate the period duopolist 1(2) acquires information. [Note the label of 1 or 2 is not related to who goes first or second.] The payoff for duopolist 1 (2) is the first (second) in each cell. Since the variances are equal, the matrices are symmetric. 
At $\mathrm{r}=0.3$, the highest payoff (15.20) for both duopolists occurs when both acquire information in the 6 th period. This is, of course, the midpoint solution $(\mathrm{T}+1) / 2$. There are no incentives for collaboration on information acquisition. When $\mathrm{r}=0.9$, there are three equilibrium solutions $(6,6),(7,7)$ and $(8,8)$. The highest payoffs of these equilibrium occurs at $(6,6)$ and thus the equilibrium solution would once again occur at $(\mathrm{T}+1) / 2$. However, note that duopolist 1 would be best off at $(7,4)$ whereas duopolist 2 would be best off at $(4,7)$, although these are not equilibrium solutions in the noncooperative game. (These points, of course, approach the solution of $(4,8)$ and $(8,4)$ obtained when $r=1$.) Each, however, would want the other to go first. In the absence of resolution of that issue, $(6,6)$ defaults to the solution.

When the variances of the two firms are different $\left(v_{1} / v_{2}\right.$ other than 1$)$, as we varied $r$ between 0 and 1 , we found that for low values of $r$ the solution was usually at $t_{1}=t_{2}=\frac{(T+1)}{2}$.

For relatively higher values of $r$, such as for $r=0.5,0.6,0.7$ with $v_{1} / v_{2}=1 / 25$, an equilibrium solution was not always possible since the issue of who went "first" came into play. Only when r approached the vicinity of 0.8 or 0.9 were incentives for information collaboration apparent, and information acquisition was staggered.

With this background, we can now turn to a discussion of the results.

\subsection{Discussion of Results}

The results indicate that when $r=1$ the firms collaborate on information acquisition, and stagger their financial year-ends. When $r=0$, both collect and release information at the same time (the half-way point). These results can be understood if we note that information in a competitive environment is valuable because it provides knowledge as to

1. the duopolist's own cost function; as well as

2. the rival's (costs and resultant) actions 
Of these two pieces of information, knowledge of one's own costs is relatively more important in terms of impact on expected profits. When $r=0$, observing the rival's costs does not provide any information regarding one's own costs. Each firm, therefore, chooses the timing of its information acquisition like a monopolist that has a single chance of acquiring information during the $\mathrm{T}$ periods, and thus both firms acquire information at the same point in time, $(\mathrm{T}+1) / 2$. When $r=1$, firms then have two sources of information for the same stochastic variable. Timing is determined then "as if" firms have two chances to acquire information during the T periods, and we have the monopolist solution for $n=2 .^{11}$

Numerical analysis indicates that simultaneous acquisition of information continues to be an equilibrium outcome even as $\mathrm{r}$ approaches 1 (e.g. Table 1 for $\mathrm{r}=0.9$ ), and staggered acquisition is an outcome only at values of $\mathrm{r}$ very close to 1 . In other words, the impact of the stochastic environment in determining the timing choice continues to dominate until the benefits of sharing are very strong - at values of $r$ close to 1 . We conjecture that if the stochastic shocks to costs were less persistent, staggered disclosure may be the outcome for lower values of $\mathrm{r}$ as well. The stochastic environment in our model is such that firms face a random but permanent shock to their costs every period. This creates a strong incentive to choose the mid-point as the optimum time for updating information. A generalization of the model would be to allow the shocks to be only semi-permanent (i.e., allow a Markovian rather than a strictly random walk structure on costs). However, this modification makes the model exceedingly complicated and does not allow for closed-form analytical solutions.

The importance of the issue of who goes first or second also explains this "discontinuity" in the results as $\mathrm{r}$ approaches 1 . Since knowledge of one's own costs is relatively more important

\footnotetext{
11 These results can be understood on a more formal basis by looking at the model in the Appendix. Note that when $r=0$ the payoff function of each firm is separable in $t_{1}$ and $t_{2}$ (Equations 8.1 and 8.2 in Appendix A3), so that the marginal contribution of changes in $t_{1}$ are independent of the choice of $t_{2}$ and vice versa. As a result each firm chooses its timing independently at the same point, $(\mathrm{T}+1) / 2$. In contrast when $\mathrm{r}=1$, the marginal contribution of changes in timing varies with the timing selected by the rival $t_{2}$ (Equations 9.1 and 9.2 in Appendix A3). Cross effects are positive in this case and hence simultaneous acquisition of information cannot be optimal. We thank the referee for pointing this out.
} 
and information acquired later has more value, each firm has strong incentive to delay that acquisition and go second. In the absence of the resolution of the issue of who goes first, $(\mathrm{T}+1) / 2$ defaults to the equilibrium solution even for relatively high values of $r$. When variances are unequal, the issue of who goes first is exacerbated, and we find that an equilibrium solution to the noncooperative game is not always possible.

We find that the factors that typically influence the degree of collaboration in information sharing studies (in which information is shared through a trade association) do not carry over to information acquisition decisions examined here. This is because in the present setting firms are always assumed to reveal information, even when $r=1$. As a result, the timing decision is motivated mainly by each firm's attempt to learn as much as possible about its own costs, and not by strategic considerations that prevent firms from revealing information to rivals through trade associations. $^{12}$ We also find that, unlike in the information sharing literature, the basic nature of our results do not change when we consider Bertrand instead of Cournot competition. ${ }^{13}$

\subsection{Empirical Implications and Generalizations}

In their study comparing the financial characteristics of December and non-December year-end firms Smith and Pourciau (1988) found that although 62\% of all firms have 12/31 as their year-end, the pattern of concentration of year-ends varies widely across industries (Table 2 , page 342). For instance, whereas more than $90 \%$ of the firms have $12 / 31$ as their financial yearend in industries such as metal mining, petroleum refining, air transport and banking, in other industries such as building construction, retail-food, hotels, business services, and automotive

\footnotetext{
${ }^{12}$ In the information sharing studies, with perfectly informative signals, information sharing leads only to improved information on the rivals' costs. As a result oligopolists will ex ante always prefer to mutually share information, irrespective of the value of $r$. They will be willing do reveal information unilaterally only at small $r$. In contrast, in our setting firms' acquisition/sharing decisions are motivated mainly by each firm's attempt to learn as much as possible about its own cost parameter. Firms learn the most from collaboration when their costs are correlated. In this setting, therefore, only when $r$ is large and near 1 is there collaboration on information acquisition.
}

13 The analysis for Bertrand competition is available from the authors upon request. 
services only about half of all firms have their year-ends at 12/31. For these latter firms, this study does not detail whether the year-ends of the remaining firms are clustered around another date, or are dispersed throughout the remainder of the year.

Our results suggests that, for the stochastic environment described above, similar firms (i.e., firms whose costs are relatively more correlated) are more likely to choose dispersed or staggered year-ends. Conversely, year-ends concentrated on a particular date are more likely to be found in industries where firms differ in terms of their cost structure, production technologies and/or product differentiation. We find these results to be relatively robust to changes in market power (i.e., increasing the number of firms) and also to changes in the nature of competition (Bertrand versus Cournot).

Many empirical studies use financial year-ends as a sample selection criteria. These results suggest that imposing a year-end restriction (usually 12/31) for sample selection may bias the sample and therefore the results. For instance, studies on intraindustry information transfers (e.g., Foster (1981) and Frost (1995)) hypothesize that the strength of such transfers is positively correlated with within-industry homogeneity. Our results suggest that the greater the withinindustry homogeneity, more likely it is for firms to choose dispersed financial year-ends. Therefore, by restricting attention to firms that have similar financial year-ends these studies may be including relatively dissimilar firms, thereby downward biasing their results.

Finally, note that one way to interpret our research question is: if firms had an incentive to choose a particular year-end(such as $1 / 31$ for retail firms), could the benefits from sharing the information acquisition burden ever be sufficient to make them deviate from this chosen year-end? In our setting, the stochastic environment made the midpoint of the time horizon the desired yearend, but if the rivals' financial report proved informative enough (i.e., costs were highly correlated) a firm was willing to deviate from this desired optimum. Thus our results can be generalized to settings where a particular year-end (such as $1 / 31$ for retail firms) would be desired, except when there are significant opportunities to learn from the competitors' publicly disclosed financial reports. 


\section{Summary and Conclusions}

In this paper we examined the optimal timing for acquiring information for a monopolist and also for duopolists, each facing stochastic but permanent shocks to his linear cost (or demand) parameter every period. We find that the monopolist prefers to spread limited number of information gathering opportunities evenly over several periods. When the duopolists choose their information acquisition/disclosure timing ex ante, the resultant agreements are a function of the degree of correlation between their costs. Only when costs are very highly correlated do the duopolists stagger the acquisition timing; otherwise, from very low (zero) to moderately high degrees of correlation, simultaneous acquisition (and disclosure) is the preferred choice.

Our results contribute towards explaining the choice of financial year-ends by firms. Compustat data for 1996 reveals that although the financial year-ends of firms are concentrated at $12 / 31$, the degree of concentration varies widely between industries. Our results indicate that

unless firms' costs are very highly correlated, competitive concerns reinforce this tendency by firms in the same industry to release information at the same time. The incentive to choose staggered financial year-ends occurs only when firms' costs are very highly correlated, as is likely to be the case for firms producing very similar products using similar technologies, such as commodities. Further research that looks at the timing issue under alternative formulations of the competitive and stochastic structure, and in settings where information acquisition and disclosure may take place at different points in time, will shed more light on this issue. 


\section{Table 1 NUMERICAL ANALYSIS}

Payoff Matrix $(\mathrm{T}=11, \mathrm{v} 1=\mathrm{v} 2=1)$

Rows (Columns) represent period duopolist 1 (2) acquires information

$$
\mathbf{r}=.3
$$

\begin{tabular}{|c|c|c|c|c|c|c|c|c|c|c|c|c|c|c|c|c|c|c|c|c|c|c|}
\hline & \multicolumn{2}{|c|}{1} & \multicolumn{2}{|c|}{2} & \multicolumn{2}{|c|}{3} & \multicolumn{2}{|c|}{4} & \multicolumn{2}{|c|}{5} & \multicolumn{2}{|c|}{6} & \multicolumn{2}{|c|}{7} & \multicolumn{2}{|c|}{8} & \multicolumn{2}{|c|}{9} & \multicolumn{2}{|c|}{10} & \multicolumn{2}{|c|}{11} \\
\hline 1 & 4.64 & 4.64 & 4.53 & 7.4 & 4.54 & 9.56 & 4.54 & 11.1 & 4.53 & 12 & 4.49 & 12.2 & 4.41 & 11.8 & .31 & 10.8 & 4.16 & 9.09 & 3.99 & 6.8 & 3.78 & 3.8 \\
\hline 2 & 7.4 & 4.53 & 8.44 & 8.44 & 8.17 & 10.5 & 8.02 & 11.9 & 7.89 & 12.7 & 7.76 & 12.8 & 7.61 & 12.4 & 7.43 & 11.2 & 7.23 & 9.48 & 6.99 & 7.1 & 6.72 & 4 \\
\hline 3 & 9.56 & 4.54 & 10.47 & 8.17 & 11.4 & 11.4 & 11 & 12.7 & 10.72 & 13.4 & 10.47 & 13.5 & 10.22 & 12.9 & 9.96 & 11.7 & 9.67 & 9.84 & 9.37 & 7.4 & 9.03 & 4.2 \\
\hline 4 & 11.08 & 4.54 & 11.89 & 8.02 & 12.7 & 11 & 13.51 & 13.5 & 13.01 & 14.1 & 12.61 & 14.1 & 12.24 & 13.4 & 11.87 & 12.1 & 11.5 & 10.2 & 11.12 & 7.6 & 10.71 & 4.4 \\
\hline 5 & 11.97 & 4.53 & 12.68 & 7.89 & 13.39 & 10.7 & 14.09 & 13 & 14.78 & 14.8 & 14.18 & 14.6 & 13.67 & 13.9 & 13.19 & 12.5 & 12.71 & 10.5 & 12.24 & 7.8 & 11.75 & 4.6 \\
\hline 6 & 12.21 & 4.49 & 12.84 & 7.76 & 13.45 & 10.5 & 14.05 & 12.6 & 14.63 & 14.2 & 15.2 & 15.2 & 14.51 & 14.3 & 13.89 & 12.9 & 13.31 & 10.8 & 12.73 & 8 & 12.15 & 4.7 \\
\hline 7 & 11.81 & 4.41 & 12.36 & 7.61 & 12.89 & 10.2 & 13.39 & 12.2 & 13.87 & 13.7 & 14.34 & 14.5 & 14.78 & 14.8 & 14 & 13.2 & 13.29 & 11 & 12.6 & 8.2 & 11.92 & 4.7 \\
\hline 8 & 10.77 & 4.31 & 11.24 & 7.43 & 11.68 & 9.96 & 12.1 & 11.9 & 12.49 & 13.2 & 12.86 & 13.9 & 13.2 & 14 & 13.51 & 13.5 & 12.65 & 11.2 & 11.84 & 8.3 & 11.05 & 4.8 \\
\hline 9 & 9.09 & 4.16 & 9.48 & 7.23 & 9.84 & 9.67 & 10.18 & 11.5 & 10.48 & 12.7 & 10.75 & 13.3 & 11 & 13.3 & 11.21 & 12.7 & 11.4 & 11.4 & 10.45 & 8.4 & 9.55 & 4.8 \\
\hline 10 & 6.77 & 3.99 & 7.08 & 6.99 & 7.36 & 9.37 & 7.61 & 11.1 & 7.83 & 12.2 & 8.02 & 12.7 & 8.17 & 12.6 & 8.29 & 11.8 & 8.38 & 10.5 & 8.44 & 8.4 & 7.42 & 4.7 \\
\hline 11 & 3.8 & 3.78 & 4.04 & 6.72 & 4.24 & 9.03 & 4.41 & 10.7 & 4.55 & 11.8 & 4.65 & 12.2 & 4.71 & 11.9 & 4.75 & 11.1 & 4.75 & 9.55 & 4.71 & 7.4 & 4.64 & 4.6 \\
\hline
\end{tabular}

$$
\mathbf{r}=.9
$$

\begin{tabular}{|c|c|c|c|c|c|c|c|c|c|c|c|c|c|c|c|c|c|c|c|c|c|c|}
\hline & \multicolumn{2}{|c|}{1} & \multicolumn{2}{|c|}{2} & \multicolumn{2}{|c|}{3} & \multicolumn{2}{|c|}{4} & \multicolumn{2}{|c|}{5} & \multicolumn{2}{|c|}{6} & \multicolumn{2}{|c|}{7} & \multicolumn{2}{|c|}{8} & \multicolumn{2}{|c|}{9} & \multicolumn{2}{|c|}{10} & \multicolumn{2}{|c|}{11} \\
\hline 1 & 1.71 & 1.71 & 83 & 83 & .39 & .82 & .84 & 4.56 & .16 & 5.02 & .34 & 22 & .39 & .15 & 3.29 & 4.82 & .05 & 4.21 & 2.67 & 3.34 & 2.14 & 2.19 \\
\hline 2 & 2.83 & 1.83 & 3.11 & 3.11 & 2.82 & 3.93 & 3.24 & 4.69 & 3.63 & 5.22 & 3.9 & 5.47 & 4.04 & 5.47 & 4.05 & 5.2 & 3.92 & 4.65 & 3.65 & 3.85 & 3.24 & 2.77 \\
\hline 3 & 3.82 & 2.39 & 3.93 & 2.82 & 4.2 & 4.2 & 3.66 & 4.76 & 3.95 & 5.3 & 4.26 & 5.6 & 4.47 & 5.65 & 4.57 & 5.44 & 4.54 & 4.96 & 4.37 & 4.21 & 4.07 & 3.2 \\
\hline 4 & 4.56 & 2.84 & 4.69 & 3.24 & 4.76 & 3.66 & 4.98 & 4.98 & 4.3 & 5.31 & 4.47 & 5.62 & 4.7 & 5.71 & 4.86 & 5.55 & 4.91 & 5.13 & 4.84 & 4.44 & 4.64 & 3.49 \\
\hline 5 & 5.02 & 3.16 & 5.22 & 3.63 & 5.3 & 3.95 & 5.31 & 4.3 & 5.44 & 5.44 & 4.71 & 5.57 & 4.79 & 5.65 & 4.94 & 5.53 & 5.05 & 5.16 & 5.05 & 4.53 & 4.94 & 3.64 \\
\hline 6 & 5.22 & 3.34 & 5.47 & 3.9 & 5.6 & 4.26 & 5.62 & 4.47 & 5.57 & 4.71 & 5.6 & 5.6 & 4.87 & 5.53 & 4.87 & 5.4 & 4.97 & 5.07 & 5.02 & 4.49 & 4.99 & 3.66 \\
\hline 7 & 5.15 & 3.39 & 5.47 & 4.04 & 5.65 & 4.47 & 5.71 & 4.7 & 5.65 & 4.79 & 5.53 & 4.87 & 5.44 & 5.44 & 4.76 & 5.19 & 4.71 & 4.85 & 4.76 & 4.31 & 4.78 & 3.53 \\
\hline 8 & 4.82 & 3.29 & 5.2 & 4.05 & 5.44 & 4.57 & 5.55 & 4.86 & 5.53 & 4.94 & 5.4 & 4.87 & 5.19 & 4.76 & 4.98 & 4.98 & 4.37 & 4.54 & 4.3 & 4.01 & 4.32 & 3.26 \\
\hline 9 & 4.21 & 3.05 & 4.65 & 3.92 & 4.96 & 4.54 & 5.13 & 4.91 & 5.16 & 5.05 & 5.07 & 4.97 & 4.85 & 4.71 & 4.54 & 4.37 & 4.2 & 4.2 & 3.7 & 3.6 & 3.63 & 2.87 \\
\hline 10 & 3.34 & 2.67 & 3.85 & 3.65 & 4.21 & 4.37 & 4.44 & 4.84 & 4.53 & 5.05 & 4.49 & 5.02 & 4.31 & 4.76 & 4.01 & 4.3 & 3.6 & 3.7 & 3.11 & 3.11 & 2.74 & 2.34 \\
\hline 11 & 2.19 & 2.14 & 2.77 & 3.24 & 3.2 & 4.07 & 3.49 & 4.64 & 3.64 & 4.94 & 3.66 & 4.99 & 3.53 & 4.78 & 3.26 & 4.32 & 2.87 & 3.63 & 2.34 & 2.74 & 1.71 & 1.71 \\
\hline
\end{tabular}




\section{Appendix A1}

\section{Proof of Proposition 1: Solution to the Monopolist's Problem}

From equation (6) we have the monopolist's expected profit (at time $t_{\mathrm{o}}$ ) equal to

$$
\mathrm{P}^{*}=\frac{T A^{2}}{4}+\sum_{\mathrm{i}=2}^{\mathrm{n}}\left(\mathrm{t}_{\mathrm{i}}-\mathrm{t}_{\mathrm{i}-1}\right) \frac{\mathrm{t}_{\mathrm{i}-1} \mathrm{v}^{2}}{4}+\left(\mathrm{T}+1-\mathrm{t}_{\mathrm{n}}\right) \frac{\mathrm{t}_{\mathrm{n}} \mathrm{v}^{2}}{4}
$$

Taking derivatives with respect to $t_{i}$ yields

$$
\frac{d P^{*}}{d t_{i}}=\frac{\mathrm{t}_{\mathrm{i}-1} \mathrm{v}^{2}}{4}+\frac{\mathrm{t}_{\mathrm{i}+1} \mathrm{v}^{2}}{4}-\frac{2 \mathrm{t}_{\mathrm{i}} \mathrm{v}^{2}}{4} \quad \text { for } \mathrm{i}=2 \ldots . \mathrm{n}-1
$$

For $\mathrm{i}=1$

$$
\frac{d P^{*}}{d t_{1}}=\frac{\mathrm{t}_{2} \mathrm{v}^{2}}{4}-\frac{2 \mathrm{t}_{1} \mathrm{v}^{2}}{4}
$$

For $\mathrm{i}=\mathrm{n}$

$$
\frac{d P^{*}}{d t_{n}}=\frac{\mathrm{t}_{\mathrm{n}-1} \mathrm{v}^{2}}{4}+\frac{(\mathrm{T}+1) \mathrm{v}^{2}}{4}-\frac{2 \mathrm{t}_{\mathrm{n}} \mathrm{v}^{2}}{4}
$$

Setting the derivatives equal to 0 and solving yields

$$
\begin{aligned}
& t_{1}=\frac{t_{2}}{2} \\
& t_{i}=\frac{t_{i-1}+t_{i+1}}{2} \\
& t_{n}=\frac{(T+1)+t_{n+1}}{2}
\end{aligned}
$$

Information is acquired at equal intervals over the $\mathrm{T}$ periods.

\section{Appendix A2}

\section{Expected Profit Functions for the Duopolists:}

- At $t_{1}$, the "first" duopolist acquires and discloses information $\mathrm{C}_{\mathrm{f}}\left(\mathrm{t}_{1}\right)$ : 
Based on that information, the expected cost of the second duopolist is equal to

$$
\mathrm{E}\left(\mathrm{C}_{\mathrm{s}}\left(\mathrm{t}_{1}\right) \mid \mathrm{C}_{\mathrm{f}}\left(\mathrm{t}_{1}\right)\right)=\mathrm{c}+\mathrm{b}_{\mathrm{f}} \mathrm{C}_{\mathrm{f}}\left(\mathrm{t}_{1}\right),
$$

with $\mathrm{c}$ is the deterministic component of costs, set equal to 0 , and $\mathrm{b}_{\mathrm{f}}=\mathrm{rv}_{\mathrm{s}} / \mathrm{v}_{\mathrm{f}}$, .

Therefore,

$$
\mathrm{q}_{\mathrm{f}}\left(\mathrm{t}_{1}\right)=\frac{\mathrm{A}-2 \mathrm{C}_{\mathrm{f}}\left(\mathrm{t}_{1}\right)+\mathrm{E}\left(\mathrm{C}_{\mathrm{s}}\left(\mathrm{t}_{1}\right) \mid \mathrm{C}_{\mathrm{f}}\left(\mathrm{t}_{1}\right)\right)}{3}=\frac{\mathrm{A}}{3}+\frac{\left(\mathrm{b}_{\mathrm{f}}-2\right) \mathrm{C}_{\mathrm{f}}\left(\mathrm{t}_{1}\right)}{3}
$$

and Expected Profits are

$$
P_{f}^{*}\left(t_{1}\right)=\frac{A^{2}}{9}+\frac{\left(b_{f}-2\right)^{2} t_{1} v_{f}^{2}}{9}
$$

where $\frac{A^{2}}{9}$ is the expected profits in the absence of any information.

Similarly, for the "second" duopolist

$$
\begin{aligned}
& \mathrm{q}_{\mathrm{s}}\left(\mathrm{t}_{1}\right)=\frac{\mathrm{A}-2 \mathrm{E}\left(\mathrm{C}_{\mathrm{s}}\left(\mathrm{t}_{1}\right) \mid \mathrm{C}_{\mathrm{f}}\left(\mathrm{t}_{1}\right)\right)+\mathrm{C}_{\mathrm{f}}\left(\mathrm{t}_{1}\right)}{3}=\frac{\mathrm{A}}{3}+\frac{\left(1-2 \mathrm{~b}_{\mathrm{f}}\right) \mathrm{C}_{\mathrm{f}}\left(\mathrm{t}_{1}\right)}{3} \\
& \mathrm{P}_{\mathrm{s}}^{*}\left(\mathrm{t}_{2}\right)=\frac{A^{2}}{9}+\frac{\left(1-2 \mathrm{~b}_{\mathrm{f}}\right)^{2} \mathrm{t}_{1} \mathrm{v}_{\mathrm{f}}^{2}}{9}
\end{aligned}
$$

- At $t_{2}$, "second" duopolist acquires and discloses information $\mathrm{C}_{2}\left(\mathrm{t}_{2}\right)$

$\mathrm{E}\left(\mathrm{C}_{\mathrm{f}}\left(\mathrm{t}_{2}\right)\right)$ is conditional on both $\mathrm{C}_{\mathrm{f}}\left(\mathrm{t}_{1}\right)$ and $\mathrm{C}_{\mathrm{s}}\left(\mathrm{t}_{2}\right)$. The variance-covariance matrix $\sum$ for the variables $\mathrm{C}_{\mathrm{f}}\left(\mathrm{t}_{2}\right), \mathrm{C}_{\mathrm{s}}\left(\mathrm{t}_{2}\right), \mathrm{C}_{\mathrm{f}}\left(\mathrm{t}_{1}\right)$, in that order, is

Therefore,

$$
\Sigma=\left(\begin{array}{ccc}
t_{2} v_{f}^{2} & t_{2} r v_{f} v_{s} & t_{1} v_{f}^{2} \\
t_{2} r v_{f} v_{s} & t_{2} v_{s}^{2} & t_{1} r v_{f} v_{s} \\
t_{1} v_{f}^{2} & t_{1} r v_{f} v_{s} & t_{1} v_{f}^{2}
\end{array}\right)
$$

$$
E\left(C_{f}\left(t_{2}\right) \mid C_{f}\left(t_{1}\right), C_{s}\left(t_{2}\right)\right)=\left[\begin{array}{lll}
t_{2} r_{f} v_{s} & t_{1} v_{f}^{2}
\end{array}\right] \times \sum_{23}^{-1} \times\left[\begin{array}{lll}
C_{s}\left(t_{2}\right) & C_{f}\left(t_{1}\right)
\end{array}\right]^{T}
$$

where $\sum_{23}$ is the matrix comprised of the second and third rows/columns of $\Sigma$. i.e.,

$$
\sum_{23}=\left(\begin{array}{cc}
t_{2} v_{s}^{2} & t_{1} r v_{f} v_{s} \\
t_{1} r v_{f} v_{s} & t_{1} v_{f}^{2}
\end{array}\right)
$$

It follows that 


$$
\mathrm{E}\left(\mathrm{C}_{\mathrm{f}}\left(\mathrm{t}_{2}\right) \mid \mathrm{C}_{\mathrm{f}}\left(\mathrm{t}_{1}\right), \mathrm{C}_{\mathrm{s}}\left(\mathrm{t}_{2}\right)\right)=\mathrm{GC}_{\mathrm{f}}\left(\mathrm{t}_{1}\right)+\mathrm{Hb}_{\mathrm{s}} \mathrm{C}_{\mathrm{s}}\left(\mathrm{t}_{2}\right)
$$

$$
\text { where } G=\left(\frac{t_{2}\left(1-r^{2}\right)}{t_{2}-t_{1} r^{2}}\right) \text { and } H=\left(\frac{t_{2}-t_{1}}{t_{2}-t_{1} r^{2}}\right)
$$

Therefore:

$$
\begin{aligned}
& \mathrm{q}_{\mathrm{f}}\left(\mathrm{t}_{2}\right)=\frac{\mathrm{A}-2 \mathrm{E}\left(\mathrm{C}_{\mathrm{f}}\left(\mathrm{t}_{2}\right) \mid \mathrm{C}_{\mathrm{f}}\left(\mathrm{t}_{1}\right), \mathrm{C}_{\mathrm{s}}\left(\mathrm{t}_{2}\right)\right)+\mathrm{C}_{\mathrm{s}}\left(\mathrm{t}_{2}\right)}{3}=\frac{\mathrm{A}}{3}+\frac{\mathrm{C}_{\mathrm{s}}\left(\mathrm{t}_{2}\right)\left(1-2 \mathrm{Hb}_{\mathrm{s}}\right)-2 \mathrm{GC}_{\mathrm{f}}\left(\mathrm{t}_{1}\right)}{3} \\
& \mathrm{P}_{\mathrm{f}}\left(\mathrm{t}_{2}\right)=\frac{\mathrm{A}^{2}}{9}+\frac{\left(1-2 \mathrm{Hb}_{\mathrm{s}}\right)^{2} \mathrm{t}_{2} \mathrm{v}_{\mathrm{s}}^{2}}{9}+\frac{4 \mathrm{G}^{2} \mathrm{t}_{1} \mathrm{~V}_{\mathrm{f}}^{2}}{9}+\frac{4\left(2 \mathrm{Hb}_{\mathrm{s}}-1\right) \mathrm{Gt}_{1} \mathrm{rv}_{\mathrm{f}} \mathrm{v}_{\mathrm{s}}}{9}
\end{aligned}
$$

and

$$
\begin{aligned}
& \mathrm{q}_{\mathrm{s}}\left(\mathrm{t}_{2}\right)=\frac{\left.\mathrm{A}-2 \mathrm{C}_{\mathrm{s}}\left(\mathrm{t}_{2}\right)\right)+\mathrm{E}\left(\mathrm{C}_{\mathrm{f}}\left(\mathrm{t}_{2}\right) \mid \mathrm{C}_{\mathrm{f}}\left(\mathrm{t}_{1}\right), \mathrm{C}_{\mathrm{s}}\left(\mathrm{t}_{2}\right)\right)}{3}=\frac{\mathrm{A}}{3}+\frac{\mathrm{C}_{\mathrm{s}}\left(\mathrm{t}_{2}\right)\left(\mathrm{Hb}_{\mathrm{s}}-2\right)+\mathrm{GC}_{\mathrm{f}}\left(\mathrm{t}_{1}\right)}{3} \\
& \mathrm{P}_{\mathrm{s}}\left(\mathrm{t}_{2}\right)=\frac{\mathrm{A}^{2}}{9}+\frac{\left(\mathrm{Hb}_{\mathrm{s}}-2\right)^{2} \mathrm{t}_{2} \mathrm{v}_{\mathrm{s}}^{2}}{9}+\frac{\mathrm{G}^{2} \mathrm{t}_{1} \mathrm{v}_{\mathrm{f}}^{2}}{9}+\frac{2\left(\mathrm{Hb}_{\mathrm{s}}-2\right) \mathrm{Gt}_{1} \mathrm{rv}_{\mathrm{f}} \mathrm{v}_{\mathrm{s}}}{9}
\end{aligned}
$$

Now for any duopolist, $(i=f$ or $s), \frac{A^{2}}{9}$ is earned for $\left(t_{1}-1\right)$ periods, $P_{i}\left(t_{1}\right)$ is earned for $\left(t_{2}-t_{1}\right)$

periods and $P_{i}\left(t_{2}\right)$ is earned for $\left(T+1-t_{2}\right)$ periods. Therefore, overall profit to be maximized is

$$
P_{i}^{*}=\frac{A^{2}}{9}\left(t_{1}-1\right)+P_{i}^{*}\left(t_{1}\right)\left(t_{2}-t_{1}\right)+P_{i}^{*}\left(t_{2}\right)\left(T+1-t_{2}\right)
$$

which yields:

$$
\begin{aligned}
& \mathrm{P}_{\mathrm{f}}^{*}=\mathrm{T} \frac{\mathrm{A}^{2}}{9}+\left[\frac{\left(\mathrm{b}_{\mathrm{f}}-2\right)^{2} \mathrm{t}_{1} \mathrm{v}_{\mathrm{f}}^{2}}{9}\right]\left(\mathrm{t}_{2}-\mathrm{t}_{1}\right)+\left[\frac{\left(1-2 \mathrm{Hb}_{\mathrm{s}}\right)^{2} \mathrm{t}_{2} \mathrm{v}_{\mathrm{s}}^{2}}{9}+\frac{4 \mathrm{G}^{2} \mathrm{t}_{1} \mathrm{v}_{\mathrm{f}}^{2}}{9}+\frac{4\left(2 \mathrm{Hb}_{\mathrm{s}}-1\right) \mathrm{Gt}_{1} \mathrm{rv}_{\mathrm{f}} \mathrm{v}_{\mathrm{s}}}{9}\right]\left(\mathrm{T}+1-\mathrm{t}_{2}\right) \\
& \mathrm{P}_{\mathrm{s}}^{*}=\mathrm{T} \frac{\mathrm{A}^{2}}{9}+\left[\frac{\left(1-2 \mathrm{~b}_{\mathrm{f}}\right)^{2} \mathrm{t}_{\mathrm{v}} \mathrm{v}_{\mathrm{f}}^{2}}{9}\right]\left(\mathrm{t}_{2}-\mathrm{t}_{1}\right)+\left[\frac{\left(H \mathrm{Hb}_{\mathrm{s}}-2\right)^{2} \mathrm{t}_{2} \mathrm{v}_{\mathrm{s}}^{2}}{9}+\frac{\mathrm{G}^{2} \mathrm{t}_{1} \mathrm{v}_{\mathrm{f}}^{2}}{9}+\frac{2\left(\mathrm{Hb}_{\mathrm{s}}-2\right) \mathrm{Gt}_{1} \mathrm{rv}_{\mathrm{f}} \mathrm{v}_{\mathrm{s}}}{9}\right]\left(\mathrm{T}+1-\mathrm{t}_{2}\right)
\end{aligned}
$$

\section{Appendix A3}

\section{Proof of Proposition 2:}

When $r=0, b_{f}=b_{s}=0$ and $G=1$. Therefore, from (7.1) and (7.2),

$$
P_{f}^{*}=T \frac{A^{2}}{9}+\left[\frac{4 t_{1} v_{f}^{2}}{9}\right]\left(t_{2}-t_{1}\right)+\left[\frac{t_{2} v_{s}^{2}}{9}+\frac{4 t_{1} v_{f}^{2}}{9}\right]\left(T+1-t_{2}\right)
$$




$$
\begin{aligned}
& =T \frac{A^{2}}{9}+\frac{t_{2} v_{s}^{2}}{9}\left(T+1-t_{2}\right)+\frac{4}{9} t_{1} v_{f}^{2}\left(T+1-t_{1}\right) \\
P_{s}^{*} & =T \frac{A^{2}}{9}+\left[\frac{t_{1} v_{f}^{2}}{9}\right]\left(t_{2}-t_{1}\right)+\left[\frac{4 t_{2} v_{s}^{2}}{9}+\frac{t_{1} v_{f}^{2}}{9}\right]\left(T+1-t_{2}\right) \\
& =T \frac{A^{2}}{9}+\frac{t_{1} v_{f}^{2}}{9}\left(T+1-t_{1}\right)+\frac{4}{9} t_{2} v_{s}^{2}\left(T+1-t_{2}\right)
\end{aligned}
$$

Maximizing $\mathrm{P}_{\mathrm{f}}^{*}$ with respect to $\mathrm{t}_{1}$ and $\mathrm{P}_{\mathrm{s}}^{*}$ with respect to $\mathrm{t}_{2}$ yields

$\frac{\mathrm{dP}_{\mathrm{f}}}{\mathrm{dt}_{1}}=\left[\frac{4 \mathrm{v}_{\mathrm{f}}^{2}}{9}\right](\mathrm{T}+1)-\frac{8}{9} \mathrm{t}_{1} \mathrm{v}_{\mathrm{f}}^{2} \quad$ and $\quad \frac{\mathrm{dP}_{\mathrm{s}}}{\mathrm{dt}_{2}}=\left[\frac{4 \mathrm{v}_{\mathrm{s}}^{2}}{9}\right](\mathrm{T}+1)-\frac{8}{9} \mathrm{t}_{2} \mathrm{v}_{\mathrm{f}}^{2}$

Setting the derivatives equal to zero and solving for $t_{1}$ and $t_{2}$ yields the results.

\section{Proof of Proposition 3:}

When $\mathrm{r}=1, \mathrm{G}=0$ and $\mathrm{H}=1$. Therefore, from (7.1) and (7.2),

$\mathrm{P}_{\mathrm{f}}^{*}=\mathrm{T} \frac{\mathrm{A}^{2}}{9}+\left[\frac{\left(\mathrm{b}_{\mathrm{f}}-2\right)^{2} \mathrm{t}_{1} \mathrm{v}_{\mathrm{f}}^{2}}{9}\right]\left(\mathrm{t}_{2}-\mathrm{t}_{1}\right)+\left[\frac{\left(1-2 \mathrm{~b}_{\mathrm{s}}\right)^{2} \mathrm{t}_{2} \mathrm{v}_{\mathrm{s}}^{2}}{9}\right]\left(\mathrm{T}+1-\mathrm{t}_{2}\right)$

$\mathrm{P}_{\mathrm{s}}^{*}=\mathrm{T} \frac{\mathrm{A}^{2}}{9}+\left[\frac{\left(1-2 \mathrm{~b}_{\mathrm{f}}\right)^{2} \mathrm{t}_{1} \mathrm{v}_{\mathrm{f}}^{2}}{9}\right]\left(\mathrm{t}_{2}-\mathrm{t}_{1}\right)+\left[\frac{\left(\mathrm{b}_{\mathrm{s}}-2\right)^{2} \mathrm{t}_{2} \mathrm{v}_{\mathrm{s}}^{2}}{9}\right]\left(\mathrm{T}+1-\mathrm{t}_{2}\right)$

Maximizing $\mathrm{P}_{\mathrm{f}}{ }^{*}$ with respect to $\mathrm{t}_{1}$ and setting it equal to 0 , we get

$\frac{\mathrm{dP}_{\mathrm{f}}}{\mathrm{dt}_{1}}=\frac{\left(\mathrm{b}_{\mathrm{f}}-2\right)^{2}}{9} \mathrm{t}_{2} \mathrm{v}_{\mathrm{f}}^{2}-\frac{2\left(\mathrm{~b}_{\mathrm{f}}-2\right)^{2}}{9} \mathrm{t}_{1} \mathrm{v}_{\mathrm{f}}^{2}=0$, which yields

$\mathrm{t}_{1}=\frac{\mathrm{t}_{2}}{2}$

Similarly, Maximizing $\mathrm{P}_{\mathrm{s}}{ }^{*}$ with respect to $\mathrm{t}_{2}$ and setting it equal to 0 , we get 
$\frac{\mathrm{dP}_{\mathrm{s}}}{\mathrm{dt}_{2}}=\frac{\left(1-2 \mathrm{~b}_{\mathrm{f}}\right)^{2}}{9} \mathrm{t}_{1} \mathrm{v}_{\mathrm{f}}^{2}+\frac{\left(\mathrm{b}_{\mathrm{s}}-2\right)^{2}}{9} \mathrm{v}_{\mathrm{s}}^{2}(\mathrm{~T}+1)-\frac{2\left(\mathrm{~b}_{\mathrm{s}}-2\right)^{2}}{9} \mathrm{t}_{2} \mathrm{v}_{\mathrm{s}}^{2}=0$

since $\frac{v_{f}}{v_{s}}=b_{s}$

$t_{2}=\frac{T+1}{2}+\frac{\left(1-2 b_{f}\right)^{2} b_{s}^{2} t_{1}}{2\left(b_{s}-2\right)^{2}}$

since $b_{\mathrm{f}} b_{\mathrm{s}}=1$

$\mathrm{t}_{2}=\frac{\mathrm{T}+1}{2}+\frac{\mathrm{t}_{1}}{2}$

Using the expression for $t_{1}$ above gives the result

$\mathrm{t}_{2}=\frac{2(\mathrm{~T}+1)}{3}$

$\mathrm{t}_{1}=\frac{\mathrm{T}+1}{3}$ 


\section{REFERENCES}

Darrough, M. [1993] "Disclosure Policy and Competition: Cournot vs. Bertrand," The Accounting Review 68:534-561.

Dontoh, A. [1990] "Voluntary Disclosure," Journal of Accounting, Auditing and Finance 4: 480-511.

Fried, D. [1984] "Incentive for Information Production and Disclosure in a Duopolistic Environment," Quarterly Journal of Economics 99: 367-381.

Foster, G. [1981] "Intraindustry Information Transfers Associated with Earnings Release," Journal of Accounting and Economics, 3: 201-232.

Hansen, Steven C. and Mandira Roy Sankar [1998] “ Cost Stability and the Periodic Review Cycle," Working Paper, University of California, Los Angeles.

Hughes, John S. [1975] “Optimal Timing of Cost Information," Journal of Accounting Research 13: 344-349.

Hughes, John S. [1977] “Optimal Timing of Cost Information: Author's Correction,” Journal of Accounting Research 15: 313-316.

Jin, Y., [1992] "Information Sharing in Oligopoly," Doctoral Dissertation, Purdue University.

Kirby, A. [1988] "Trade Associations as Information Exchange Mechanisms," RAND Journal of Economics 19: 138-146.

Kirby, A. [1993] "Self-Imposed Information Acquisition and Disclosure: An Economic Analysis," Working Paper, University of California, Berkeley.

Li, Lode, Richard D. McKelvey and Talbot Page [1987] "Optimal Research for Oligopolists," Journal of Economic Theory 42: 140-166.

Novshek, W., and H. Sonnenschein [1982] "Fulfilled Expectations Cournot Duopoly with Information Acquisition and Release," Bell Journal of Economics, 13: 214-218.

Raith, M. A. [1993], "A General Model of Information Sharing in Oligopoly," Working Paper, London School of Economics.

Sakai, Y. [1986] "Cournot and Bertrand Equilibria under Imperfect Information," Journal of Economics, 46: 213-232.

Schipper, K. [1990] "Commentary on Information Transfers," Accounting Horizons, December: 97-107. 
Shapiro, C. [1986] "Exchange of Cost Information in Oligopoly," International Journal of Industrial Organization, 53: 433-466.

Smith, D. and S. Pourciau [1988] "A Comparison of the Financial Characteristics of December and Non-December Year-End Companies," Journal of Accounting and Economics, 10: $335-44$ 